\title{
Roland Barthes, Le Neutre
}

\section{Rachele Raus}

\section{OpenEdition}

\section{Journals}

Édition électronique

URL : http://journals.openedition.org/studifrancesi/36867

DOI : 10.4000/studifrancesi.36867

ISSN : 2421-5856

\section{Éditeur}

Rosenberg \& Sellier

\section{Édition imprimée}

Date de publication : 1 juillet 2005

Pagination : 212

ISSN : 0039-2944

\section{Référence électronique}

Rachele Raus, «Roland Barthes, Le Neutre », Studi Francesi [En ligne], 145 (XLIX | I) | 2005, mis en ligne le 30 novembre 2015, consulté le 18 avril 2021. URL : http://journals.openedition.org/studifrancesi/ 36867 ; DOI : https://doi.org/10.4000/studifrancesi.36867

\section{Ce document a été généré automatiquement le 18 avril 2021.}

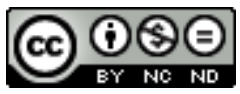

Studi Francesi è distribuita con Licenza Creative Commons Attribuzione - Non commerciale - Non opere derivate 4.0 Internazionale. 


\section{Roland Barthes, Le Neutre}

Rachele Raus 


\section{RÉFÉRENCE}

ROLAND BARTHES, Le Neutre, Paris, Seuil, 2002, pp. 269,

1 Ce livre, présenté par Thomas Clerc, consiste en la transcription du cours sur Le Neutre que Barthes fit de février à juin 1978 au Collège de France pour la chaire de Sémiologie littéraire. Il s'agit de l'analyse de 23 «traits» ou «scintillations», c'est-à-dire de fragments de textes étudiés de façon transversale à partir d'une catégorie commune (par exemple arrogance, conflit, silence, androgyne, ...). Le fait de choisir des textes tant occidentaux qu'orientaux fait émerger de façon indirecte la présence d'une idéosphère occidentale, c'est-à-dire d'un système langagier inhérent à l'idéologie occidentale.

2 L'A. essaie de dépasser la langue, qui fige déjà par son aspect assertif, passant par le discours. D'où la nécessité d'étudier ces 23 catégories en en récupérant la production, l'énonciation. Le livre est un dépassement des oppositions binaires de Saussure, dépassement qui passe par une réflexion sur l'époché husserlienne et la dialectique du zen. Le Neutre est alors défini en tant que ce qui «déjoue le paradigme», à savoir ce qui dépasse l'opposition de deux termes virtuels permettant de produire le sens (ex. Dieu existe là où il est également question de Lucifer / du mal). En ce sens, le Neutre n'est pas le nul, la renonciation à l'opposition, mais son dépassement, son ouverture au pluriel. Ainsi, la catégorie adjectif, par exemple, est considérée comme enfermant le sens, parce qu'assertive et donc idéologique par nature: «un adjectif, ça enferme toujours (l'autre, moi), c'est même la définition de l'adjectif: prédiquer, c'est affirmer, donc enfermer» (p. 94). Cependant, le participe présent sous forme adjectivale, en tant qu'activité, est un adjectif «bon». Pour ne pas enfermer le sens des autres adjectifs, il faudrait un désir du Neutre qui permettrait d'«accepter le prédicat comme un simple moment: un temps» (p. 94). Le livre se clôt sur une annexe élaborée par Thomas Clerc à partir des notes de l'A. 